\title{
GMR
}

\section{Indices estimated using REML/BLUP and introduction of a super-trait for the selection of progenies in popcorn}

\author{
C. Vittorazzi, A.T. Amaral Junior, A.G. Guimarães, A.P. Viana, \\ F.H.L. Silva, G.F. Pena, R.F. Daher, I.F.S Gerhardt, \\ G.H.F. Oliveira and M.G. Pereira ${ }^{1}$ \\ Laboratório de Melhoramento Genético Vegetal, \\ Centro de Ciências e Tecnologia Agropecuária, \\ Universidade Estadual do Norte Fluminense Darcy Ribeiro, \\ Campos dos Goytacazes, RJ, Brasil \\ Corresponding author: A.T. Amaral Junior \\ E-mail: amaraljr@uenf.br
}

Genet. Mol. Res. 16 (3): gmr16039769

Received June 30, 2017

Accepted August 24, 2017

Published September 27, 2017

DOI http://dx.doi.org/10.4238/gmr16039769

Copyright $(C 2017$ The Authors. This is an open-access article distributed under the terms of the Creative Commons Attribution ShareAlike (CC BY-SA) 4.0 License.

\begin{abstract}
Selection indices commonly utilize economic weights, which become arbitrary genetic gains. In popcorn, this is even more evident due to the negative correlation between the main characteristics of economic importance - grain yield and popping expansion. As an option in the use of classical biometrics as a selection index, the optimal procedure restricted maximum likelihood/best linear unbiased predictor (REML/BLUP) allows the simultaneous estimation of genetic parameters and the prediction of genotypic values. Based on the mixed model methodology, the objective of this study was to investigate the comparative efficiency of eight selection indices estimated by REML/ BLUP for the effective selection of superior popcorn families in the eighth intrapopulation recurrent selection cycle. We also investigated the efficiency of the inclusion of the variable "expanded popcorn volume
\end{abstract}

Genetics and Molecular Research 16 (3): gmr16039769 
per hectare" in the most advantageous selection of superior progenies. In total, 200 full-sib families were evaluated in two different areas in the North and Northwest regions of the State of Rio de Janeiro, Brazil. The REML/BLUP procedure resulted in higher estimated gains than those obtained with classical biometric selection index methodologies and should be incorporated into the selection of progenies. The following indices resulted in higher gains in the characteristics of greatest economic importance: the classical selection index/values attributed by trial, via REML/BLUP, and the greatest genotypic values/expanded popcorn volume per hectare, via REML. The expanded popcorn volume per hectare characteristic enabled satisfactory gains in grain yield and popping expansion; this characteristic should be considered super-trait in popcorn breeding programs.

Key words: Zea mays L.; Mixed model; Selection index

\section{INTRODUCTION}

The breeding programs have been dynamic and have tested some proposals of changes, always seeking to improve the efficiency of the selection process and facilitate assessments. In this sense, the combined selection is important; also important is the acquisition of superior materials from the selection and recombination of superior families and individuals for a set of features (Hallauer et al., 2010; Cruz et al., 2014). From this perspective, the main objective is to select cultivars with high yields and other desirable traits (Baker, 1986; Magnussen, 1990; Falconer and Mackay, 1996). Thus, selection should be based on a set of traits that enables the simultaneous acquisition of satisfactory genetic gains. The aim of this selection is the identification of genotypes that meet the modern demands of the consumer and producer markets (Hallauer et al., 2010; Cruz et al., 2014).

The use of a selection index, which is established using the optimum combination of several traits, is a biometric technique that allows for the efficient and simultaneous selection of multiple traits (Cruz et al., 2014). The application of selection indices enables the identification of superior genotypes established by the optimal linear combination of various traits; it is preferred that these traits be uncorrelated (Magnussen, 1990; Falconer and Mackay, 1996; Hallauer et al., 2010). The use of selection indices was originally reported by Smith (1936) and Hazel (1943). Other indices were later proposed and are currently used in plant breeding. A special emphasis has been placed on the indices developed by Williams (1962), Pesek and Baker (1969), and Mulamba and Mock (1978). Regardless of the index considered, the use of indices allows the objective determination of the relative merits of a series of genotypes and provides a basis for their differentiation (Carena, 2009).

The REML method, developed by Patterson and Thompson (1971), has been routinely used to estimate variance components in mixed models. Its wide use can be attributed to the fact that it considers all the desirable properties of an estimator. The BLUP procedure (Henderson, 1973) minimizes the variance of the prediction error and maximizing precision. BLUP is a linear function of the observations and does not account for patterns; therefore, it maximizes the accuracy of non-biased predictors and predicts random variables (Viana et al., 2011; Resende et al., 2012).

Genetics and Molecular Research 16 (3): gmr16039769 
Resende (2007a) reported that the simultaneous analysis of various traits could be efficiently performed using the multivariate REML/BLUP approach. In this case, the multivariate model is specified to address the existing environmental covariance between traits. The use of the sum of the predicted breeding values by a multivariate model, an additive index with or without economic weights, is an efficient selection strategy. BLUP increases selective accuracy; therefore, it is superior to any other combined selection index (Resende, 2007a).

The selection indices have been widely used in popcorn (Daros et al., 2004; Amaral Júnior et al., 2010) and genetic gains were predicted with satisfactory accuracy, which led to an appropriate performance of breeding programs for this culture. However, the use of selection indices is limited, in some situations, by the difficulty in establishing economic weights for the various traits. Due to these difficulties, Cruz (1990) proposed that economic weights be estimated based on experimental data. A multitrait selection procedure is needed to select simultaneously for improvement in more than one trait. The most important characteristics evaluated in popcorn breeding programs are grain yield (GY) and popping expansion (PE) (Silva et al., 2010; Moterle et al., 2011). PE is the primary quality characteristic of popcorn; this trait comprises the ratio between the volume of expanded popcorn and the initial volume or mass of grains before popping (Moterle et al., 2011; Rodovalho et al., 2014). The negative correlation between the two major characteristics of popcorn (Dofing et al., 1991; Daros et al., 2004) makes breeding difficult, but not impossible. Nevertheless, the selection process becomes biased. This is because it is not possible to uniquely and reliably associate the best genotypes for GY with the best genotypic expressions of PE. In the present study, we present the use of the following alternative trait: expanded popcorn volume per hectare (PV). We evaluated the convenience of its use as a super-trait in breeding programs.

Research into the use of selection indices via REML/BLUP in popcorn breeding programs has been limited. We compared eight selection indices based on mixed modeling to determine the reliability of the selection of the best full-sibling families in the eighth cycle of an intrapopulation recurrent selection program.

\section{MATERIAL AND METHODS}

\section{Study population}

A total of 200 full-sib families were obtained in the eighth intrapopulation recurrent selection cycle and evaluated. The evaluated families belong to the Popcorn Genetic Breeding Program of the State University of North Fluminense Darcy Ribeiro (UENF).

\section{Experimental design}

The experiments were planted in two environments in April 2013. The first experiment was conducted at the Antônio Sarlo State Agricultural College in the municipality of Campos dos Goytacazes, which is in the Northern region of the State of Rio de Janeiro, Brazil. The climate is classified as Aw (tropical savanna climate), with dry in winter according to the Köppen classification. The average annual rainfall is $1023 \mathrm{~mm}$, and the average annual temperature is $23^{\circ} \mathrm{C}$. The second experiment was conducted at the Agricultural Research Company of the State of Rio de Janeiro (Empresa de Pesquisa Agropecuária do Estado do Rio de Janeiro - PESAGRO-Rio). The Agricultural Experiment Station at Ilha do Pomba is in

Genetics and Molecular Research 16 (3): gmr16039769 
the municipality of Itaocara, which is in the Northwest region of the State of Rio de Janeiro, Brazil. The climate is classified as Awi (tropical wet-dry isotherm), with rainy summers and dry winters according to the Köppen classification. The average annual temperature is near $22.5^{\circ} \mathrm{C}$, and the average annual rainfall is $1041 \mathrm{~mm}$.

The experiments were arranged in a randomized block design with three repetitions. The plots were comprised of one row measuring $5.0 \mathrm{~m}$ in length, with $0.90 \mathrm{~m}$ spacing between the rows. The spacing between the plants was $0.20 \mathrm{~m}$. Three seeds were planted per hole at a depth of $0.05 \mathrm{~m}$. Thinning was performed at 21 days after emergence; one vigorous plant was left per hole. Fertilization was performed at planting with $800 \mathrm{~kg} / \mathrm{ha}$ mineral fertilizer in the formulation 04-14-08 (N-P-K). Topdressing was conducted at 15 days after sowing, with $300 \mathrm{~kg} / \mathrm{ha}$ mineral fertilizer in the formulation 20-00-20 (N-P-K). A second top-dressing was performed at 30 days after emergence; nitrogen in the form of urea was applied at $200 \mathrm{~kg} /$ ha. All fertilizers were recommended according to an analysis of the soil in the plantation areas. The management of weeds, pests, and diseases was carried out according to standard recommendations for the region. The GY was corrected to $13 \%$ of moisture content.

\section{Traits evaluated}

Six important agronomic characteristics were evaluated for popcorn. a) The average plant height $(\mathrm{PH})$ of six competitive plants in a plot was measured from the ground to the insertion point of the flag leaf and was expressed in meters (m). b) Prolificacy (PROL) reflected the average number of ears per plant. c) The mass of 100 grains (M100) was expressed in grams $(\mathrm{g})$ and obtained by weighing 100 grains randomly. Three repetitions were performed per plot. d) The GY was determined by weighing the grains from each plot and was expressed as $\mathrm{kg} / \mathrm{ha}$. e) PE was determined by placing $30 \mathrm{~g}$ seeds in kraft paper bags; the bags were placed in a microwave oven for $3 \mathrm{~min}$. Three repetitions were performed per experimental unit. The volume of the expanded popcorn after microwaving was quantified in a $2000-\mathrm{mL}$ beaker. PE was expressed as $\mathrm{mL} / \mathrm{g}$. f) The PV was obtained by multiplying the average yield of the plot and the PE. This measurement represents the volume of expanded popcorn by hectare planted and was expressed as $\mathrm{m}^{3} / \mathrm{ha}$.

\section{Genetic-statistical analyses}

The genetic-statistic model utilized was as follows:

$$
Y=X_{r}+Z_{g}+W_{p}+T_{i}+e
$$

(Equation 1)

where $Y$ is the vector of the data, $r$ is the vector of the repetition effects (assumed to be fixed) added to the overall average, $g$ is the vector of individual genotypic effects (assumed to be random), $p$ is the vector of environmental effects (assumed to be random), $i$ is the vector of genotype $\mathrm{x}$ environment interaction effects (random), and $e$ is the vector of errors or residues (random).

The procedures for estimating the breeding values and for executing the additive (Smith, 1936; Hazel, 1943) and multiplicative selection indices (Subandi and Empig, 1973) and the index weighted by the average rank of the families were adapted from Mulamba and Mock (1978); these procedures were performed using the SELEGEN- REML/BLUP software (Resende, 2007b).

Genetics and Molecular Research 16 (3): gmr16039769 
After the genotypic values (GV) for each family and variable were estimated, different models of the selection indices were compared and examined for the best population selection gains. The following models were used: i) selection via major $\mathrm{GV}$ associated with the variables GY and PE (GV/GY-PE); ii) selection via the greatest GV for the variable PV (GV/PV); iii) the use of the classical selection index (CI), according to the model:

$$
\boldsymbol{C I}=\left(\left(p \cdot \overline{X_{1}}\right) \cdot\left(\boldsymbol{G} \boldsymbol{V} \cdot \overline{X_{1}}\right)\right)+\ldots+\left(\left(p \cdot \overline{X_{n}}\right) \cdot\left(G \boldsymbol{V} \cdot{\overline{X_{n}}}_{n}\right)\right) \quad \text { (Equation 2) }
$$

iv) the use of the multiplicative index (MI), according to the model:

$$
M I=\left(G V \cdot \overline{X_{1}}\right) \cdot\left(G V \cdot \overline{X_{n}}\right)
$$

and v) the use of the index weighted by the average rank of the families households (IWR). IWR is described as follows:

$$
\boldsymbol{I W R}=\left(\boldsymbol{r} \cdot \boldsymbol{G} \boldsymbol{V} \cdot \overline{\boldsymbol{X}_{1}}\right)+\left(\boldsymbol{r} \cdot \boldsymbol{G} \boldsymbol{V} \cdot \overline{\boldsymbol{X}_{n}}\right)
$$

where $p$ corresponds to the economic weight attributed to the trait, $G V$ is the predicted genotypic value, $r$ corresponds to the family rank, and $\bar{X}$ corresponds to the phenotypic average of the genotype for each variable analyzed (Resende, 2007b).

For the execution of the classical index, economic weights were assigned to the characteristics using estimates of the following parameters: i) genetic coefficient of variation $(\mathrm{CVg})$; ii) genetic standard deviation $(\mathrm{SDg})$; iii) heritability $\left(\mathrm{h}^{2}\right)$; and iv) values attributed by trial (BT) of magnitude, as described by Santos et al. (2007a). Genetic parameters were assigned economic weights according to the needs of the employee selection index. The averages for these parameters were obtained by performing analysis of variance using the Genes software (Cruz, 2013); random environmental effects and the genotypes analyzed were considered.

We selected 30 superior families according to each index and fixed a $15 \%$ selection pressure. The efficiency of the selection indices was obtained using the coincidence index of the families selected by the eight selection methods employed. The index of coincidence was obtained by the ratio between twice the number of families, in which both selection indexes coincide, and the sum of the total number of families containing the selection index A plus the total number of progenies containing the selection index B (Pedrozo et al., 2009; Freitas et al., 2013). Predicted selection gains were also obtained for each characteristic evaluated using the different selection indices.

\section{RESULTS}

Based on the scores related to the additive genetic values of the 200 families, it was possible to select the 30 best families based on the largest reliably estimated genotypic values for the characteristics PE and GY (Figure 1).

Genetics and Molecular Research 16 (3): gmr16039769 


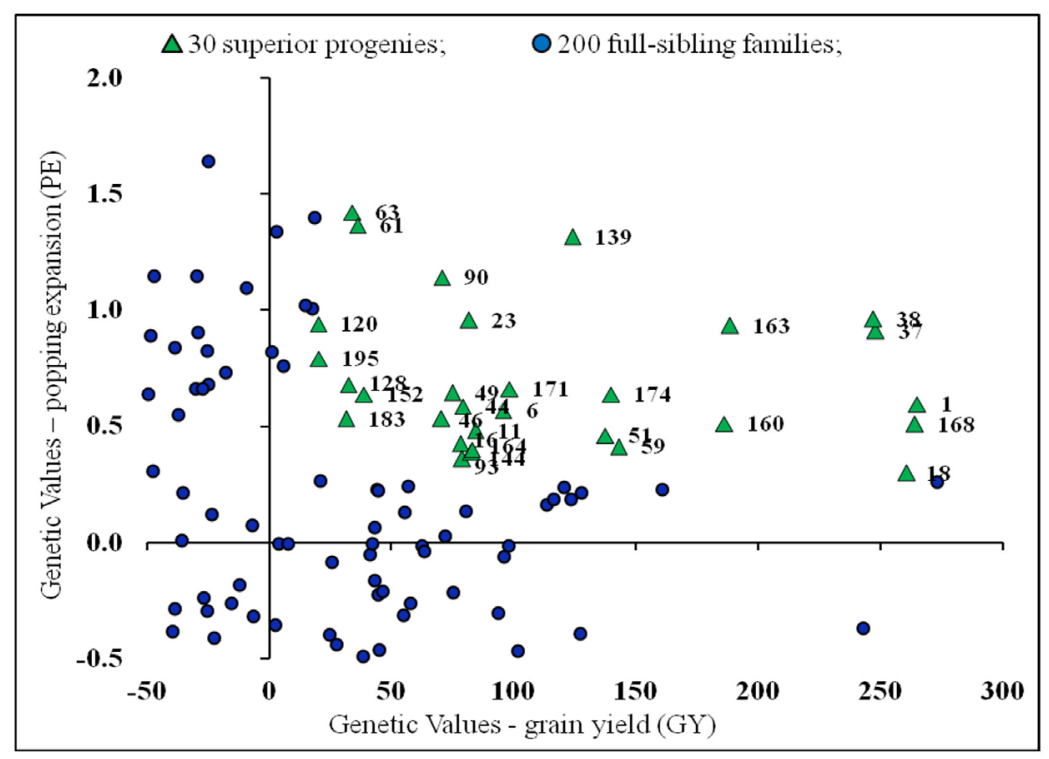

Figure 1. Graphic dispersion of 200 full-sibling families of popcorn and identification of 30 superior progenies in the eighth intrapopulation recurrent selection cycle based on additive genetic values of the characteristics popping expansion and grain yield.

For most of the coefficients, an increased degree of coincidence was observed among the families selected using the eight different selection indices. The highest coincidence (96.67\%) was observed between the indices CI/CVg and MI (Table 1).

Table 1. Coincidence coefficients (\%) for 30 superior full-sibling families identified using eight selection indices based on genotypic values for six characteristics (the traits were evaluated in the eighth intrapopulation recurrent selection cycle of the popcorn population UNB-2U).

\begin{tabular}{l|c|c|c|c|c|c|c}
\hline $\begin{array}{l}\text { Selection } \\
\text { indexes }\end{array}$ & $\mathrm{CI} / \mathrm{SDg}$ & $\mathrm{CI} / \mathrm{h}^{2}$ & $\mathrm{CI} / \mathrm{BT}$ & $\mathrm{MI}$ & $\mathrm{IWR}$ & $\mathrm{GV} / \mathrm{GY}-\mathrm{PE}$ & $\mathrm{GV} / \mathrm{PV}$ \\
\hline $\mathrm{CI} / \mathrm{CVg}$ & 73.33 & 86.67 & 83.33 & 96.67 & 80.00 & 53.33 & 76.67 \\
\hline $\mathrm{CI} / \mathrm{SDg}$ & - & 66.67 & 70.00 & 70.00 & 66.67 & 43.33 & 70.00 \\
\hline $\mathrm{CI} / \mathrm{h}^{2}$ & & - & 86.67 & 90.00 & 86.67 & 53.33 & 76.67 \\
\hline $\mathrm{CI} / \mathrm{BT}$ & & & - & 80.00 & 80.00 & 66.67 & 90.00 \\
\hline $\mathrm{MI}$ & & & & - & 76.67 & 50.00 & 73.33 \\
\hline $\mathrm{IWR}$ & & & & & - & 60.00 & 73.33 \\
\hline $\mathrm{GV} / \mathrm{GY}-\mathrm{PE}$ & & & & & & - & 63.33 \\
\hline
\end{tabular}

$\mathrm{CI} / \mathrm{CVg}$ : a classical index assigning genetic variation coefficient values as economic weights; CI/SDg: a classical index assigning values of the genetic standard deviation as economic weights; $\mathrm{CI} / \mathrm{h}^{2}$ : a classical index assigning values of heritability as economic weights; CI/BT: a classical index assigning values by trial as economic weights; MI: a multiplicative index: IWR: an index weighted by the average rank of families; GV/GY-PE: selection via the highest genotypic values assigned to the variables GY and PE; GV/PV: selection via the highest genotypic values for the variable PV.

The GV/ PV index showed values higher than $70 \%$ of coincidence with the other selection indices used in the selection of families. The highest coincidence based on GV/PV index (90\%) was observed with the CI/BT index. The index based on GV/GY-PE showed the lower values of coincidence when compared to the other indices.

Genetics and Molecular Research 16 (3): gmr16039769 
The GV/PV index showed the highest predicted percentage gain for the super-trait $\mathrm{PV}$, with an increase of $10.29 \%$ in the next cycle for this population. Furthermore, the highest value for GY was CI/SDg (9.88\%), and PE was GV/GY-PE (2.29\%) (Table 2).

Table 2. Percentage gains for eight selection indices based on breeding values for six agronomic characteristics evaluated in the eighth intrapopulation recurrent selection cycle in full-sibling families of the popcorn population UNB-2U.

\begin{tabular}{|c|c|c|c|c|c|c|}
\hline \multirow[t]{2}{*}{ Selection indexes } & \multicolumn{6}{|c|}{ Traits } \\
\hline & $\mathrm{PH}$ & PROL & M100 & GY & PE & PV \\
\hline $\mathrm{CI} / \mathrm{CVg}$ & 2.14 & 6.58 & 4.57 & 8.46 & 1.47 & 9.43 \\
\hline $\mathrm{CI} / \mathrm{SDg}$ & 2.03 & 5.13 & 1.90 & 9.88 & 0.53 & 9.38 \\
\hline $\mathrm{CI} / \mathrm{h}^{2}$ & 2.74 & 5.40 & 5.15 & 8.03 & 1.57 & 9.16 \\
\hline $\mathrm{CI} / \mathrm{BT}$ & 2.21 & 4.55 & 3.64 & 8.43 & 2.08 & 10.19 \\
\hline MI & 2.33 & 7.08 & 4.77 & 8.26 & 1.23 & 8.96 \\
\hline IWR & 2.60 & 6.03 & 3.53 & 7.85 & 1.90 & 9.43 \\
\hline GV/GY-PE & 1.95 & 1.46 & 2.04 & 5.93 & 2.29 & 8.14 \\
\hline GV/PV & 2.13 & 4.38 & 2.29 & 8.40 & 2.05 & 10.29 \\
\hline
\end{tabular}

$\mathrm{CI} / \mathrm{CVg}$ : a classical index assigning genetic variation coefficient values as economic weights; $\mathrm{CI} / \mathrm{SDg}$ : a classical index assigning values of the genetic standard deviation as economic weights; $\mathrm{CI} / \mathrm{h}^{2}$ : a classical index assigning values of heritability as economic weights; CI/BT: a classical index assigning values by trial as economic weights; MI: a multiplicative index: IWR: an index weighted by the average rank of families; GV/GY-PE: selection via the highest genotypic values assigned to the variables GY and PE; GV/PV: selection via the highest genotypic values for the variable PV. PH: average plant height; PROL: prolificacy; M100: a mass of 100 grains; GY: grain yield; PE: popping expansion; PV: expanded popcorn volume per hectare.

The predicted percentage gains (Table 2) revealed that the selection performed using genotypic values based on the GV/GY-PE index resulted in the identification of plants with lower average heights when compared to the other indices. However, this index was not suitable for the prediction of high gains in general; rather, it was suitable for PE only where the prediction gains were satisfactory.

\section{DISCUSSION}

Several studies have reported the selection for the most important characteristics in popcorn breeding; PE and GY (Santos et al., 2007a; Ribeiro et al., 2012; Freitas et al., 2014). Matta and Viana (2003) evaluated different selection methodologies among and within half-sibling families in the popcorn population; the values observed demonstrated the zero correlation between PE and GY. These authors suggested that selection for both characteristics is feasible. When selecting the best families for PE, the families with high GY are selected simultaneously, despite the aggravating null correlation factor presented by these traits. It should also be said that, among full-sib progenies, which is the case of this study, part of the dominance variance is also capitalized, thus allowing higher gains for selection, compared to the use of half-sib families (Souza Júnior and Pinto, 2000; Santos et al., 2007b; Hallauer et al., 2010). Vilarinho et al. (2002) selected for $P E$ in $S_{1}$ and $S_{2}$ popcorn progenies and obtained significant gains for both PE and GY. When performing selection directly for GY, simultaneous selection for PE was not possible due to negative PE values. Because these traits are negatively correlated, direct selection via genotypic values of the characteristics becomes compromised (Dofing et al., 1991; Daros et al., 2004; Santos et al., 2007a; Rangel et al., 2011a).

Among the coincidence ratios obtained, the higher values were found when comparing the CI/CVg and MI (Table 1); these findings confirmed those obtained by Pedrozo et al. (2008).

Genetics and Molecular Research 16 (3): gmr16039769 
These authors compared the efficiency of selection indices via the REML/BLUP methodology in three sugarcane populations. The greatest coincidence was observed between the high indices, although the coincidence values were relatively low. Freitas et al. (2013) performed a study of popcorn that compared selection indices and prediction methods via BLUP for the evaluation of genetic gain. These authors observed low coincidence values among the selection indices. The high degree of coincidence between the indices is considered a great estimate, as the results of selection between the different indices tend to be more consistent with a greater degree of coincidence between the families and the selected genotypes (Pedrozo et al., 2009).

It can be observed that the lowest coincidence rates were found when comparing selection via the genotypic values of GY and PE. Imbalance occurs in the selection of superior genotypes for other characteristics because this method considers only the two variables as a source of classification. These variables express null or negative correlations (Daros et al., 2004; Santos et al., 2007a; Rangel et al., 2011a); selection based only on these characteristics results in a lower coincidence index compared to other indices.

The predicted gain for GY (Table 2) was verified based on the GV/GY-PE index. It was observed that selection via the genetic values of GY and PE was not appropriate; compared to other indices, high gains were not observed. This can be explained by the null or negative correlations between these characteristics observed in other studies (Daros et al., 2004; Santos et al., 2007a; Rangel et al., 2011a).

Considering the predicted selection gains for GY and PE, the selection index via the genotypic values of popcorn volume (GV/PV) and the classical index with weights attributed by trial $(\mathrm{CI} / \mathrm{BT})$ showed the highest estimates for the two characteristics together. Using the $\mathrm{CI} / \mathrm{BT}$ index, the estimates were $8.43 \%$ for GY and $2.08 \%$ for PE. Using the GV/PV index, the estimates were $8.40 \%$ for GY and $2.05 \%$ for PE. The last index resulted in greater selection gains for the most important characteristics. This form of selection can be easily employed for the acquisition of gains in popcorn breeding programs. This efficiency is because important characteristics simultaneously combine both PE and GY. This form of selection is therefore of use in future recurrent selection cycles.

The effectiveness of gains predicted by the GV/PV can be compared with the gains found by the classical index (CI/BT). Santos et al. (2007a) predicted genetic gains in a popcorn population and found that the indices of Smith (1936) and Hazel (1943) resulted in the highest percentage gains for the characteristics GY and PE when arbitrary weights were assigned to the traits. Use of the CI/BT index with weights attributed by the genetic standard deviation $(\mathrm{CI} / \mathrm{SDg})$ resulted in the highest percentage gain for GY. This procedure contemplates the greater weight attributed to GY, as the genetic standard deviation used as an economic weight is far superior to other deviations of the characteristics evaluated. In general, this index did not show efficiency in gains for the other characteristics. This resulted in a lower magnitude for PE compared to all indices, with an estimate of $0.53 \%$ (Table 2).

In previous recurrent selection cycles of the UNB-2U population, the largest simultaneous gains for GY and PE were obtained using the index described by Mulamba and Mock (1978) with economic weight attributed by the trials. Gains were 8.53, 15.30, and 7.78\% for GY and 6.01, 10.97, and 5.11\% for PE in the fifth, sixth, and seventh selection cycles, respectively (Rangel et al., 2011b; Ribeiro et al., 2012; Freitas et al., 2014). In the eighth selection cycle, the gains obtained by the same index were considerably lower; the percentage gains were $4.6 \%$ for GY and 3.61\% for PE (Guimarães AG, Amaral Junior AT, Lima VJ, Leite

Genetics and Molecular Research 16 (3): gmr16039769 
JT, et al., unpublished results). Therefore, $\mathrm{CI} / \mathrm{BT}$ and GV/PV were satisfactory in optimizing the selection of superior families for GY and PE. Good results were observed; the predicted gains for GY using the CI/BT and GV/PV indices were 8.43 and $8.40 \%$, respectively (Table 2).

The gains predicted using the GV/PV index confirm that PV serves as a super-trait in the selection of popcorn progenies. This trait can be used to discriminate, via unification, families that are simultaneously superior for GY and PE.

\section{CONCLUSIONS}

The indices $\mathrm{CI} / \mathrm{BT}$, obtained via REML/BLUP, and GV/PV, obtained via REML, provided the most satisfactory results for the selection of superior GY and PE gains.

The insertion of the characteristic PV resulted in simultaneously optimized gains for GY and PE without the need to use arbitrary weights assigned to the trial. PV should be used as a "super-trait" in recurrent popcorn selection programs.

\section{Conflicts of interest}

The authors declare no conflict of interest.

\section{ACKNOWLEDGMENTS}

The authors thank the Foundation for Research Support of the State of Rio de Janeiro (FAPERJ) and the National Council for Scientific and Technological Development (CNPq) for financial support to the experiment, and the Coordination of Improvement of Higher Education Personnel (CAPES) for granting a doctoral scholarship to C. Vitorazzi.

\section{REFERENCES}

Amaral Júnior AT, Freitas Júnior SP, Rangel RM, Pena GF, et al. (2010). Improvement of a popcorn population using selection indexes from a fourth cycle of recurrent selection program carried out in two different environments. Genet. Mol. Res. 9: 340-347. https://doi.org/10.4238/vol9-1gmr702

Baker RJ (1986). Selection indices in plant breeding. CRC Press, Boca Raton.

Carena MJ (2009). Handbook of plant breeding: cereals. Springer, New York.

Cruz CD (1990). Multivariate Techniques Applied in Plant Breeding. PhD dissertation, Escola Superior de Agricultura "Luiz de Queiroz", Universidade de São Paulo.

Cruz CD (2013). GENES - a software package for analysis in experimental statistics and quantitative genetics. Acta Sci. Agron. 35: 271-276. https://doi.org/10.4025/actasciagron.v35i3.21251

Cruz CD, Carneiro PCS and Regazzi AJ (2014). Biometrical Models Applied to Breeding and Genetics. Editora UFV, Viçosa.

Daros M, Amaral Júnior AT, Pereira MG, Santos FS, et al. (2004). Recurrent selection in inbred popcorn families. Sci. Agr 61: 609-614. https://doi.org/10.1590/S0103-90162004000600008

Dofing SM, D'Croz-Mason N and Thomas-Compton MA (1991). Inheritance of expansion volume and yield in two popcorn x dent corn crosses. Crop Sci. 31: 715-718. https://doi.org/10.2135/cropsci1991.0011183X003100030035x

Falconer DS and Mackay TF (1996). Introduction to quantitative genetics. Longman Scientific \& Technical, New York.

Freitas ILJ, Amaral Jr AT, Viana AP, Pena GF, et al. (2013). Genetic gain evaluated with selection indices and with REML/ BLUP in popcorn. Pesqui. Agropecu. Bras. 48: 1464-1471. https://doi.org/10.1590/S0100-204X2013001100007

Freitas ILJ, do Amaral Júnior AT, Freitas Jr SP, Cabral PDS, et al. (2014). Genetic gains in the UENF-14 popcorn population with recurrent selection. Genet. Mol. Res. 13: 518-527. https://doi.org/10.4238/2014.January.21.21

Hallauer AR, Carena MJ and Miranda Filho JB (2010). Quantitative genetics in maize breeding. Springer, New York.

Genetics and Molecular Research 16 (3): gmr16039769 
Hazel LN (1943). The genetic basis for constructing selection indexes. Genetics 28: 476-490.

Henderson CR (1973). Sire evaluation and genetic trends. In: Animal Breeding and Genetics Symposium in Honour (Lush J, ed.). American Society of Animal Science, Champaign, 10-41.

Magnussen S (1990). Selection index: economic weights for maximum simultaneous genetic gain. Theor. Appl. Genet. 79 : 289-293. https://doi.org/10.1007/BF01186069

Matta FDP and Viana MS (2003). Relative efficiencies of between and within half-sib families selection processes in a popcorn population. Cienc. Agrotec. 27: 548-556. https://doi.org/10.1590/S1413-70542003000300008

Moterle LM, Braccini AL, Scapim CA, Pinto RJB, et al. (2011). Combining ability of popcorn lines for seed quality and agronomic traits. Euphytica 185: 337-347. https://doi.org/10.1007/s10681-011-0458-2

Mulamba NN and Mock JJ (1978). Improvement of yield potential of the ETO blanco maize (Zea mays L.) population by breeding for plant traits. Egypt. J. Genet. Cytol. 7: 40-51.

Patterson HD and Thompson R (1971). Recovery of inter-block information when block sizes are unequal. Biometrika 58: 545-554. https://doi.org/10.1093/biomet/58.3.545

Pedrozo CÂ, Barbosa MHP, Resende MDV, Peternelli LA, et al. (2008). Selection efficiency at the initial phases in sugarcane improvement. Ceres 55: 001-008.

Pedrozo CÂ, Benites FRG, Barbosa MHP, Resende MDV, et al. (2009). Efficiency of selection indexes using the REML/ BLUP procedure in sugarcane breeding. Sci. Agr. 10: 31-36.

Pesek J and Baker RJ (1969). Desired improvement in relation to selection indices. Can. J. Plant Sci. 49: 803-804. https:// doi.org/10.4141/cjps69-137

Rangel RM, Amaral Júnior AT and Freitas Júnior SP (2011a). Association between agronomical traits and popping expansion in a popcorn population under recurrent selection. Cienc. Agrotec. 35: 225-233. https://doi.org/10.1590/ $\underline{\text { S1413-70542011000200001 }}$

Rangel RM, Amaral Júnior AT, Gonçalves LSA, Freitas Júnior SP, et al. (2011b). Biometric analysis of selection gains in popcorn population of the fifth cycle of recurrent selection. Rev. Cienc. Agron 42: 473-481. https://doi.org/10.1590/ $\underline{\text { S1806-66902011000200029 }}$

Resende MDV (2007a). Matemática e Estatística na Análise de Experimentos e no Melhoramento Genético. Embrapa Florestas, Colombo.

Resende MDV (2007b). SELEGEN-REML/BLUP. Seleção Genética Computadorizada: User's Guide. Embrapa-CNPF, Colombo.

Resende MDV, Silva FF, Lopes OS and Azevedo CF (2012). Seleção Genômica Ampla (GWS) via modelos mistos (REML/ BLUP), Inferência Bayesiana (MCMC), Regressão Aleatória Multivariada e Estatística Espacial. Editora UFV, Viçosa.

Ribeiro RM, do Amaral Júnior AT, Gonçalves LSA, Candido LS, et al. (2012). Genetic progress in the UNB-2U population of popcorn under recurrent selection in Rio de Janeiro, Brazil. Genet. Mol. Res. 11: 1417-1423. https:// doi.org/10.4238/2012.May.15.12

Rodovalho M, Mora F, Scapim CA, Arriagada O, et al. (2014). Genetic evaluation of popcorn families using a Bayesian approach via the Independence chain algorithm. Crop Breed. Appl. Biotechnol. 14: 261-265. https://doi. org/10.1590/1984-70332014v14n4n41

Santos FS, Amaral Jr AT, Freitas Jr SP, Rangel RM, et al. (2007a). Genetic gain prediction by selection index in a UNB-2U popcorn population under recurrent selection. Bragantia 66: 389-396. https://doi.org/10.1590/S0006$\underline{87052007000300004}$

Santos MFT, Câmara MM, Moro GV, Costa EFN, et al. (2007b). Responses to selection and changes in combining ability after three cycles of a modified reciprocal recurrent selection in maize. Euphytica 157: 185-194. https://doi. org/10.1007/s10681-007-9410-x

Silva VQR, Amaral Jr AT, Scapim CA, Freitas Júnior SP, et al. (2010). Inheritance for economically important traits in popcorn from distinct heterotic groups by Hayman's diallel. Cereal Res. Commun. 38: 273-285. https://doi. org/10.1556/CRC.38.2010.2.14

Smith MSAHF (1936). A discriminant function for plant selection. Ann. Hum. Genet. 7: 240-250.

Souza Júnior CL and Pinto RMC (2000). Responses to a short-term reciprocal recurrent selection procedure in maize. Maydica 45: 21-28.

Subandi WAC and Empig LT (1973). Comparison of the efficiencies of selection indices for three traits in two variety crosses of corn. Crop Sci. 13: 184-186.

Viana JMS, Faria VR, Silva FF and Resende MDV (2011). Best linear unbiased prediction and family selection in crop species. Crop Sci. 51: 2371-2381. https://doi.org/10.2135/cropsci2011.03.0153

Vilarinho AA, Viana JMS, Câmara TMM and Santos JF (2002). S1 and S2 inbred progenies selection in program for intrapopulational improvement of popcorn. Acta Sci. Agron. 24: 1419-1425. https://doi.org/10.4025/actasciagron.v24i0.2393

Williams JS (1962). The evaluation of a selection index. Biometrics 18: 375-393. https://doi.org/10.2307/2527479

Genetics and Molecular Research 16 (3): gmr16039769 